\title{
Anthropometric measurement based on structure from motion imaging technique
}

\author{
Paśko S. ${ }^{1}$, Sutkowski M. ${ }^{2}$ \\ ${ }^{1}$ Institute of Micromechanics and Photonics, Warsaw University of Technology, \\ St. A. Boboli str., 8, 02-525, Warsaw, Poland \\ ${ }^{2}$ Institute of Microelectronics and Optoelectronics, Warsaw University of Technology, \\ Nowowiejska str., 15/19, 00-665, Warsaw, Poland
}

Received 19.10.2015

Accepted for publication 14.11.2016

\begin{abstract}
The aim of this work was to estimate limitations related of the actual resolution of images taken into the object reconstruction procedure (using Structure from Motion method) applied for anthropometric measurements. This is necessary to define technical parameters of equipment used for this application.

A series of 42 images of the sample static object were taken with use of high resolution camera. The object was in a stable position, properly illuminated with stable, diffused light sources. With use of VisualSFM software a virtual cloud of points representing real points of examined object was calculated. During tests a resolution of input images were changed then the calculation time and influence of the number of points in the cloud onto deviation of selected anthropometric parameters were analyzed.

In conditions of the performed experiment decreasing of the resolution of input images to the level of $80 \%$ of initial value (or lower) has significant influence onto results of the measurements of selected anthropometric parameters.

Structure from Motion (SfM) technique can be adopted for anthropometric measurement systems when the input images are taken with high resolution imaging device (over a dozen of million pixels). Presented measurement method for anthropometry is characterized by ease of use, do not need any calibration before measurements or specialized equipment. Thank to this can be adopted in practice in any conditions and operated by unskilled operator.
\end{abstract}

Keywords: structure from motion, anthropometry.

DOI: 10.21122/2220-9506-2016-7-3-305-311

\begin{tabular}{ll}
\hline Aдрес для переписки: & Address for correspondence: \\
Paśko S. & Paśko S. \\
Institute of Micromechanics and Photonics, Warsaw University of & Institute of Micromechanics and Photonics, Warsaw University of \\
Technology, & Technology, \\
St. A. Boboli str., 8, 02-525, Warsaw, Poland & St. A. Boboli str., 8, 02-525, Warsaw, Poland \\
e-mail: s.pasko@mchtr.pw.edu.pl & e-mail: s.pasko@mchtr.pw.edu.pl \\
\hline Для цитирования: & For citation: \\
Paśko S., Sutkowski M. & Paśko S., Sutkowski M. \\
Anthropometric mеasurement based on structure from motion imaging & Anthropometric measurement based on structure from motion imaging \\
technique. & technique. \\
Приборы и методы измерений. & Pribory i metody izmerenij [Devices and Methods of Measurements]. \\
2016. - Т. 7, № 3.- С. 305-311. & 2016, vol. 7, no. 3, pp. 305-311. \\
DОI: 10.21122/2220-9506-2016-7-3-305-311 & DOI: 10.21122/2220-9506-2016-7-3-305-311
\end{tabular}




\title{
Измерения антропометрических параметров на основе технологии визуализации движения
}

\author{
Пасько С. ${ }^{1}$, Сутковский М. ${ }^{2}$ \\ ${ }^{1}$ Институт микромеханики и фотоники, Вариавский политехнический университет, \\ ул.св А Боболи, 8, 02-525, Варшава, Польша \\ ${ }^{2}$ Институт микроэлектроники и оптоэлектроники, Вариавский политехнический университет, \\ ул. Нововейская 15/19, 00-665 Варшава, Польша
}

Поступила 19.10.2015

Принята к печати 14.11.2016

Целью данной работы являлась оценка ограничений, связанных с фактическим разрешением изображений, выполненных в процессе реконструкции объекта с использованием технологии визуализации движения в измерение антропометрических параметров. Это необходимо в целях определения параметров аппаратуры, служащей для того же применения.

Посредством цифровой камеры профессионального класса с высоким разрешением была выполнена серия из 42 изображений образца статического объекта. Объект находился в одной и той же точке пространства в устойчивом положении и освещался рассеянным излучением, создаваемым стандартными источниками света со стабильными характеристиками. С использованием программного обеспечения VisualSFM была получена совокупность геометрических отсчетов - «виртуальное облако точек», представляющих собой точки, воспроизводимые на исследуемом объекте. В процессе исследований разрешение изображений изменялось, что позволило выявить отклонения выбранных антропометрических параметров и выполнить их анализ.

В условиях проведенного эксперимента уменьшение разрешения входных изображений до уровня $80 \%$ (или больше) от первоначального значения оказывает существенное влияние на результаты измерений выбранных антропометрических параметров.

Технология визуализации движения (SfM) может быть использована для антропометрических измерительных систем, когда входные изображения выполняются с высоким разрешением (более десятка миллионов пикселей). Представленный метод измерения для антропометрии характеризуется простотой использования, не требуется какой-либо калибровки перед измерениями или специализированной аппаратуры. Благодаря этому, может быть принят на практике в любых условиях и управляется неквалифицированным оператором.

Ключевые слова: технология визуализации движения (SfM), антропометрия.

DOI: $10.21122 / 2220-9506-2016-7-3-305-311$

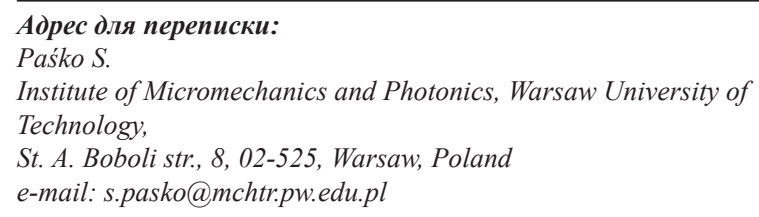

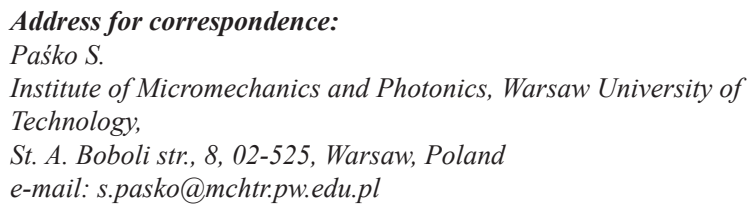




\section{Introduction}

Anthropometry refers to physical measurements of human individuals for anthropological purposes. In vivo measurements of the parameters instead of classical contact methods can be done inter alia by optical way. However the classical optical measurement systems are much more comfortable for the models (patient or examined person) and can produce results of many anthropometric values with high precision they are in general very complicated in construction and operation, moreover are expensive ones. In this paper we are presenting a low-cost optical method applied for measure anthropometric individuals of humans' face (i.e. facial index, nasal index etc.). It is also very simple for operators and do not need any physical calibration procedures. Thanks to the simplicity the measuring stand can be arranged in quite every place and can be performed by unskilled person what makes this system very portable. In the paper we discuss an influence of the image resolution onto calculation time and final results (measured values).

The measurements of anthropometric values of the humans' face are widely used in many different applications, beginning from physical anthropology, medicine (medical analysis, surgery) through security systems (face recognition) to industrial and design (clothing, ergonomics etc.). Most of these values can be determined by use of optical methods [1,2]. Many of these methods are based on image recognition and image processing. There are divided for two general branches: two-dimensional and 3D data collection [3-5]. Two-dimensional methods are limited by lack of some information (no depth data or only predicted values). However some of the applications can successfully adopt them (i.e. face recognition) they has some limitations (i.e. impossibility of measure of important anthropometric values). Thus a 3D imaging systems are much more suitable but in other hand inconvenient due to the necessity of complex build and calibration procedures.

In the paper a very simple imaging system with no calibration demand for anthropometry is presented. The system is based on widely known Structure from Motion (SfM) technique [6-9]. With use of SfM reconstruction of shape of the object from multiple camera views can be realized. The $\mathrm{SfM}$ theorem assume unknown or partially unknown parameters of the camera which may change in time additionally. Having a set of $\mathrm{n}$ images taken from $m$ fixed 3D points SfM estimate $n$ projection matrices and thus an estimated 3D points cloud of the object can be achieved (see Figure 1). The relative coordinates of the object's points can be determined and consequently relative geometrical values calculated. However in this method there is a kind of latitude allowed during measurements (no need of any additional procedures, adjustments nor calibration), SfM charges main computer performing necessary calculations very hardly.

In the application when determination of the geometrical values is needed (as in this case) the most important is to achieve as good reconstruction quality as possible to achieve best possible representation of the real world in the reconstructed scene. The number of points in a cloud in the reconstructed model in SfM method determines how precise the real object is reconstructed and is related to the resolution of the input images. The greater the number of points in the reconstructed cloud the higher accuracy is achieved. This in turn is strictly dependent on the quality of recorded images (due to a number of factors, including the number of pixels of input images).

In typical applications, the SfM method uses of images in which the number of pixels ranges from 1 to 5 mega pixels. We decided use for the collection of input images a much larger number of them - images were recorded by detector with approx. 24 million of effective pixels. Then reduction of the resolution of the input images were made to determine what the minimum number of pixels is needed to determine the correct quantity of geometric parameters registered object (parameters of the face). This is of practical importance because the reduction of the number of points is reflected in a strong reduction of processing time. In future studies, where research will be attended by more people calculation time has important practical significance.

The goal of this work is to adopt Structure from Motion technique as a tool for determination of anthropometric parameters. This kind of SfM application was never performed before. The Authors define requirements needed for use SfM in this application and verify influence of the resolution of the input images onto uncertainty of the determination of the coordinates of measured points - what in consequence will cause measurement uncertainties.

A series of images taken from fixed points (on the figure points P1, P2, P3 shows few selected camera positions only) is needed. Numerical calculations allow to determine relative $3 \mathrm{D}$ coordinates of the object's points. Collecting data of many points lead to shape reconstruction [12]. 


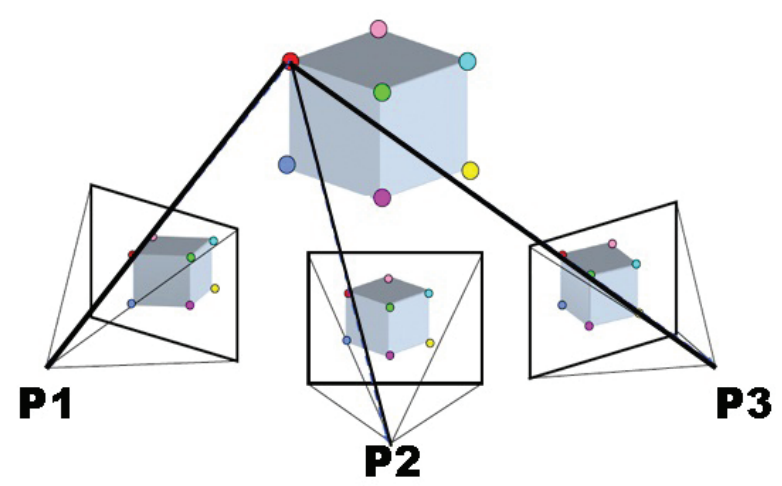

Figure 1 - The basic idea of object's point estimation with use of SfM (by commons.wikimedia.org)

\section{Shape reconstruction}

Experimental set-up used in our experiment consists of the consumer type digital photographic camera (Nikon D610, full frame sensor, 24.3 million of effective pixels) with varifocal lens (Nikkor 24$85 \mathrm{~mm}$ ) and a diffused light source (for proper and shadow free illumination of the object). A model (patient or examined person) was in a stable position on a backed chair.

For the measurements is needed to take a series of pictures from different points of view with constant exposure value and focal point placed at the object (patient or examined person). In general the more picture is taken from different angles and the better resolution of the input images the more precise shape reconstruction can be done but in consequence the more calculation time is needed. The goal of the experiment is to determine the influence of the pixel count of the corresponding series of input images on the final results of the measurements in the optical set-up for anthropometric measurements.

A series of 42 pictures with constant exposure conditions (i.e. aperture $f / 5.6$, exposure time $t=1 / 60 \mathrm{~s}$, equv. ISO $=1600$, focal length $f=50 \mathrm{~mm}$ ) from different positions were done. In the field of view a standard pattern with series of squares was placed used for absolute geometrical dimensions determination. Pictures were recorded as a RAW type (NEF) files with native camera resolution $(6016 \times 4016$ pixels $)$. Image data was processed with use of Adobe Photoshop Lightroom post-processing software. The images was sampled from RAW data to different final resolution described in percentage values of initial pixel count. As a result it was achieved a series of identical images differing only in pixel count was achieved.

To avoid possible differences in object's points determination during experiment a special circular markers were placed on the object (patient or examined person). Obviously these markers are needless when the anthropometric measurements would be performed and was applied only for these tests.

The schematic diagram of the experimental setup is shown on Figure 2.

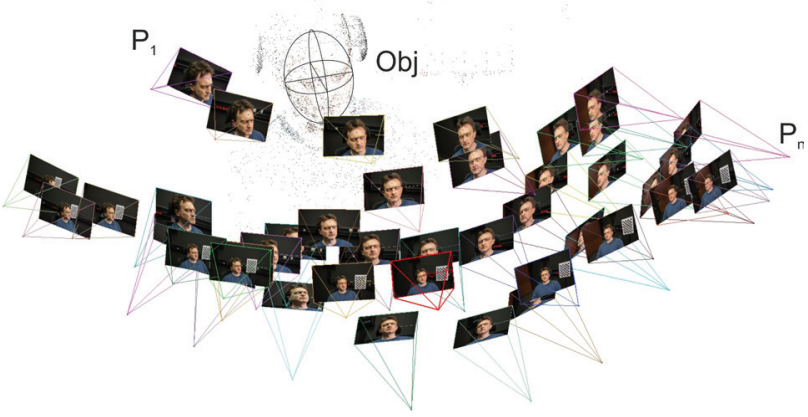

Figure 2 - Experimental set-up for anthropological values determination with use of Structure from Motion (SfM). Obj. - position of the object (patient or examined person); $P_{1} \ldots P_{n}$-points where the consequent images was taken from (for convenience only start-point and end-point are marked)

Taken images were directed to the reconstruction software which in this case was a VisualSFM v 0.5.25 [10,11]. The calculation was performed on the PC-machine equipped with CPU Intel Core i5 M520@2.40GHz, memory RAM 8GB and operating system Windows 8.1 Pro 64-bit. A series of 42 images was enough to make reconstruction of the $3 \mathrm{D}$ model of the scene. Resulting model is shown in Figure 3. The calculation time as a function of final pixel count are shown in the Table and Figure 4.

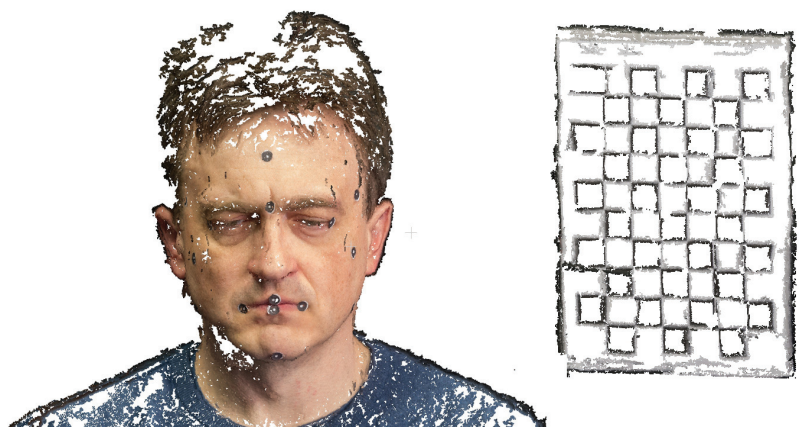

Figure 3 - Reconstructed model with use of SfM method. The standard pattern is shown on the image on the right, it was present in the scene and used for absolute dimensions determination. On the image applied markers placed on the object (patient or examined person) are visible

As expected the calculation time dramatically decreases with smaller image resolution, starting from over $45 \mathrm{~min}$ to a little bit over $4 \mathrm{~min}$. With the decreasing number of pixels of the input images a final 
number of the reconstructed points also decreased starting from approx. $625 \mathrm{k}$ points to $68 \mathrm{k}$ points. This is shown in the Table.

As a result of the experiment we took some exemplary measurements. Employing sample points (markers) on the patient's face exemplary distances in vertical and horizontal directions were determined in a function of initial resolution of series of images taken for SfM reconstruction. It is shown on Figure 5 and Figure 6 . The distances between consecutive markers taken from the cloud of points with highest density (marked as $100 \%$ ) were assigned as a reference value. Results are shown as absolute difference to this reference. As shown a difference does not exceed a level of $2 \mathrm{~mm}$ when the initial resolution is $80 \%$ or higher. When density of the cloud decreases measured distances has more uncertainty, achieving quite $\Delta=8 \mathrm{~mm}$ at the worst case. Such big uncertainty is caused by errors of the reconstruction. The more points are reconstructed in the cloud the more precise determination of the coordinates of the markers can be done and the final results in measurements are better.
In the experiment the number of the points in the cloud after reconstruction was decreased dramatically (approx. by the factor of 9, as a result of decrease of the resolution of the input images) and causes that some points are not present in the reconstructed model and thus precise determination of the coordinates of some markers is impossible. In consequence, the quality of the reconstruction has a major influence on the usefulness of the SfM method in this application.

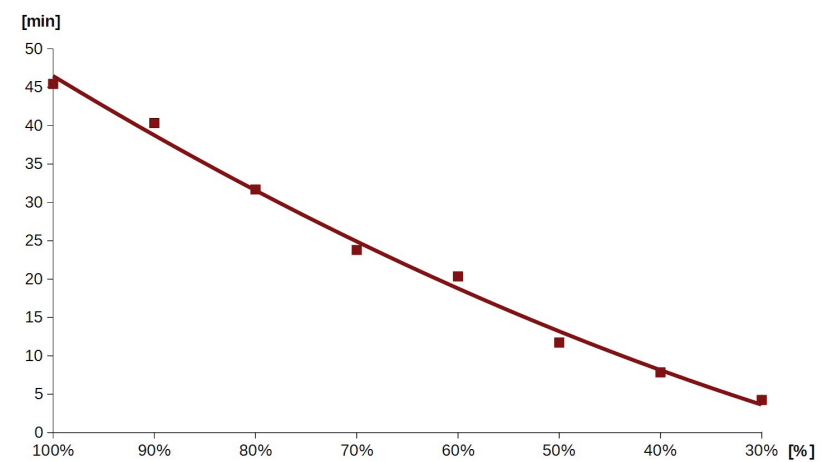

Figure 4 - Dependence of calculation time vs initial images resolution

Table

Influence of input images resolution on measured values of calculation time and the number of reconstructed points in the cloud. Resolution is shown as a resulting pixel count of camera «native» resolution $(6016 \times 4016$ pixels - $\mathbf{2 4 . 1 6}$ million of pixels). In the brackets - relative change of the parameter

\begin{tabular}{ccc}
\hline Image resolution (relative) & Points in the cloud $\left[10^{3}\right]$ & Calculation time $[\mathrm{min}]$ \\
\hline $30 \%$ & $68770(11 \%)$ & $4,25(9 \%)$ \\
\hline $40 \%$ & $116252(19 \%)$ & $7,85(17 \%)$ \\
\hline $50 \%$ & $169741(27 \%)$ & $11,73(26 \%)$ \\
\hline $60 \%$ & $259179(41 \%)$ & $20,35(45 \%)$ \\
\hline $70 \%$ & $328401(52 \%)$ & $23,8(52 \%)$ \\
\hline $80 \%$ & $430521(69 \%)$ & $31,68(70 \%)$ \\
\hline $90 \%$ & $518622(83 \%)$ & $40,33(89 \%)$ \\
\hline $100 \%$ & $625754(100 \%)$ & $45,43(100 \%)$ \\
\hline
\end{tabular}

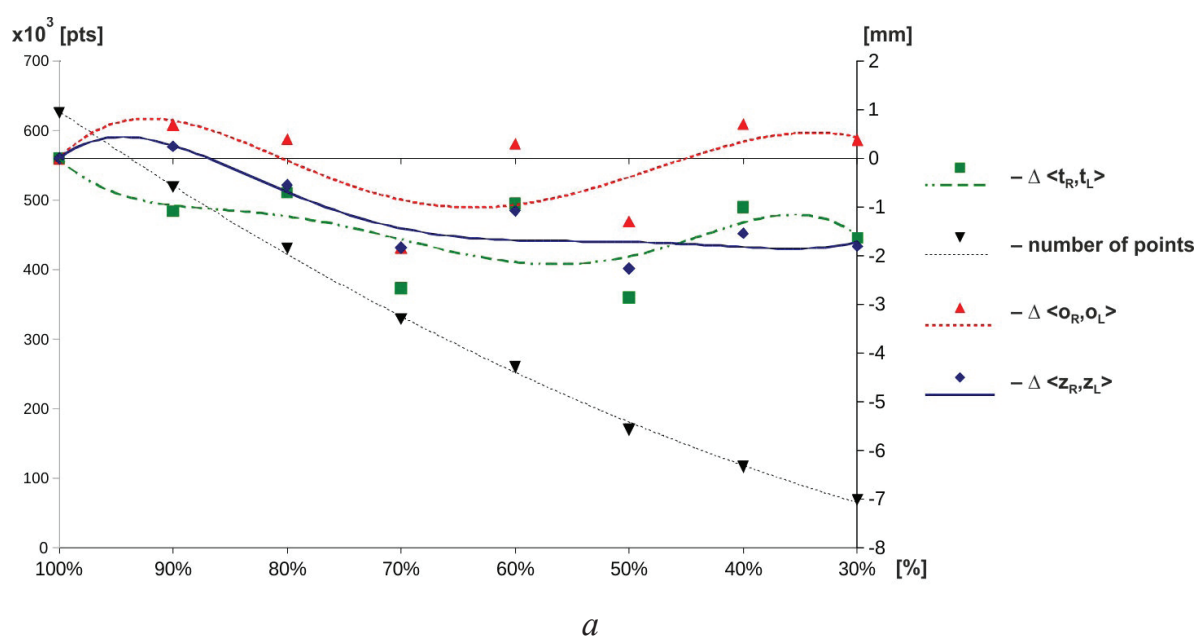



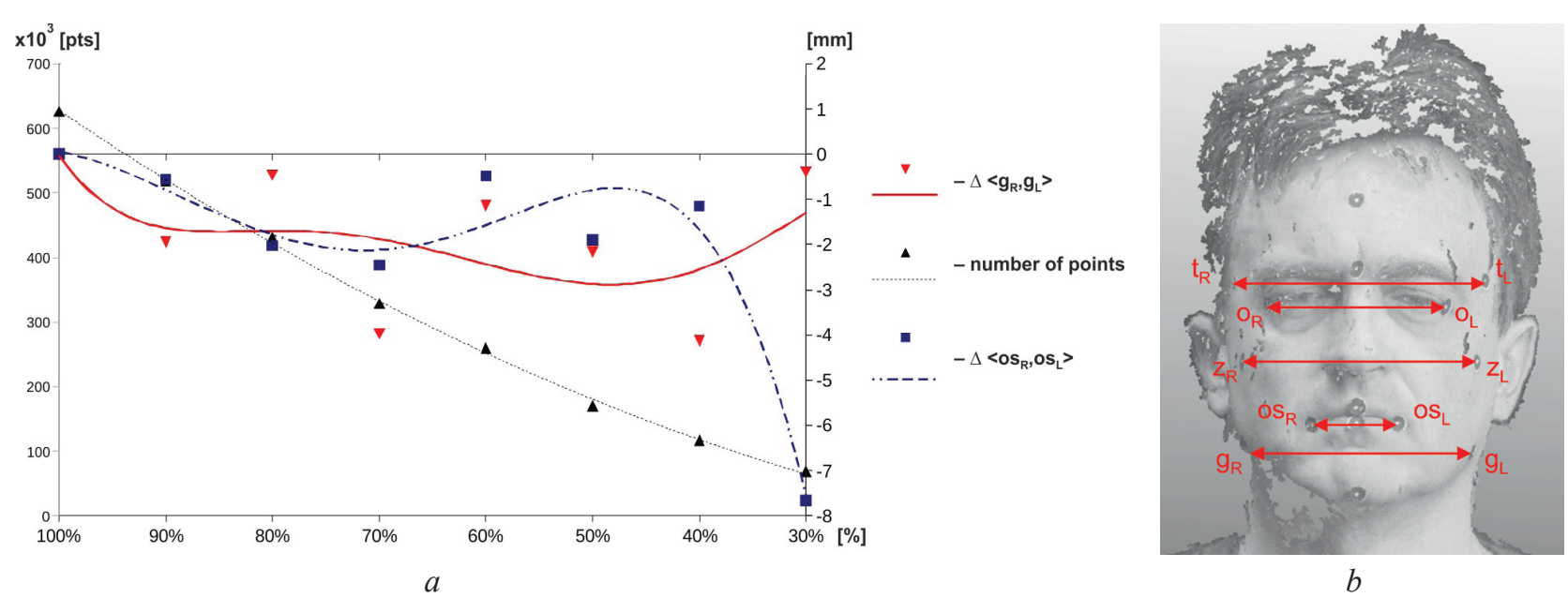

$b$

Figure 5 - Results of the determination of horizontal distances on the objects (face) $-a, b$. Selected anthropometric points were marked and exemplary dimensions were determined - c. $R, L$ indices - denotes right or left respectively; $t$ - tempus (temple); $O$ - oculus (eye); $Z$ - zygoma (zygomatic arche); $O S$ - oris (mouth edge); $g$ - angulus (gonial angle)
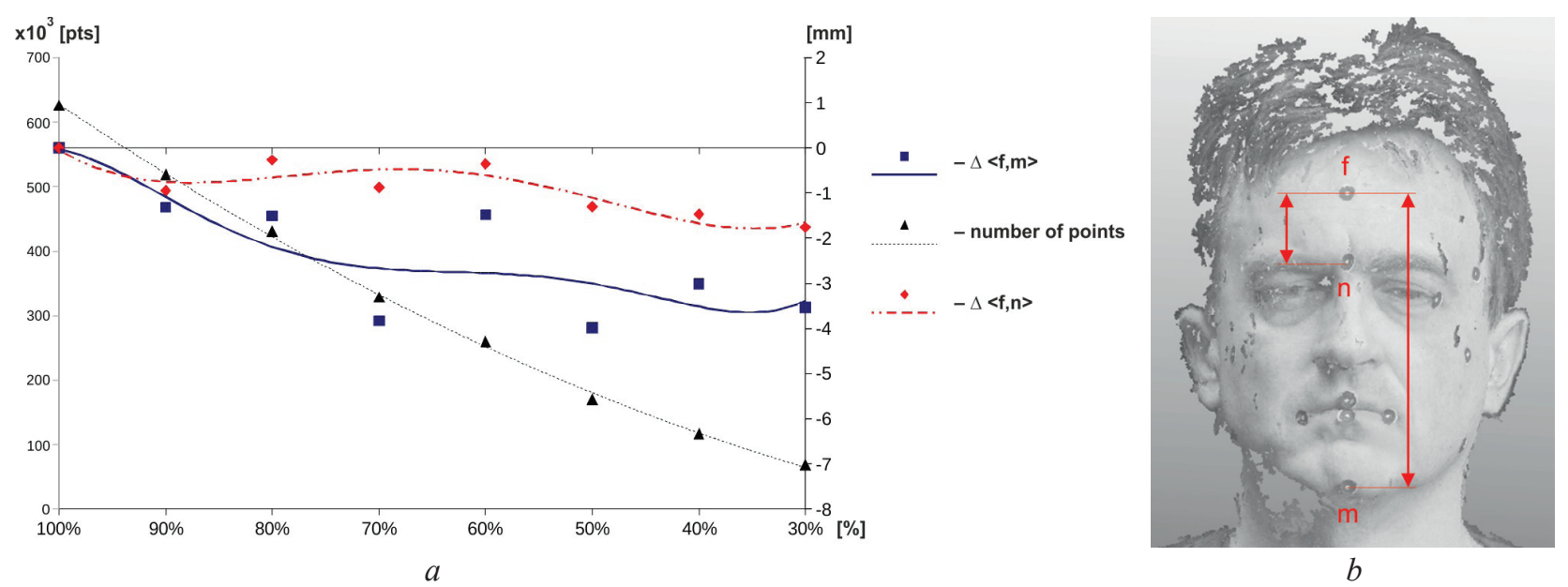

Figure 6 - Results of the determination of vertical distances on the objects (face) $-a$. Selected anthropometric points were marked and exemplary dimensions were determined $-b . R, L$ indices - denotes right or left respectively; $m$ - mentum (chin); $n$-nasus (nose); $f$ - frontis (frontal bone)

\section{Conclusion}

In the paper a simple, non-invasive and rapid method of reconstruction of the human body shape (head as an example) is presented. Thanks to its simplicity it do not demand any complicated operation nor calibration before data collection. The only need is to maintain fixed focal plane during image acquisition and constant exposure. In other hand mentioned advantages requires engagement of relatively complicated numerical procedures and thus needs powerful hardware for analysis (computers) and/or relatively long time for calculation. As a result we achieve a 3D data (shape) which allow to determine relative coordinates $(x, y, z)$ of the selected points on the examined object.

When in the scene the standard pattern is present as a reference the absolute geometrical values can be determined and thus real distances between marked points can be calculated.

The resolution of the initial images has major influence of the measure uncertainty. The lower resolution of the input images the lower number of points in the cloud (of the reconstructed object) can be calculated. And in consequence the smallest distance possible to measure is dramatically increasing and the measurement error also increases. This is the price to pay when the system has to work faster. But it has been shown that from a practical point of view, in many applications, it is not necessary to use as high resolution matrices as used here, since calculation time increases disproportionately with respect to the advantages it brings more accurately reconstructed model. In the case of experiment presented in this paper the reduction of the number of pixels in reconstructed model shows approximately 
proportional influence on the reduction of calculation time.

In practice Authors can recommend to use in the proposed application input images with resolution of 20 million of pixels or better. Thus the reconstruction consists of more number of points in the cloud (in our case more than 430 million of points) and precision of the determination of the coordinates of the markers can be satisfactory.

Thanks to the simplicity the SfM is also suitable for design and ergonomic engineering. In some of the applications the possible higher error in the measurements can be accepted and the initial images can be taken with smaller resolution and the final results can be reached quicker.

\section{References}

1. Xu B., Yu W., Yao M., Reese Pepper M., Freeland-Graves J. H. Three-dimensional surface imaging system for assessing human obesity. Opt. Eng., 2009, October, vol. 48? no. 10, nihpa156427. doi: $10.1117 / 1.3250191$

2. Stancic I., Supuk T., Cecic M. Computer vision system for human anthropometric parameters estimation. WSEAS TRANSACTIONS on SYSTEMS, 2009, iss. 3, vol. 8 , pp. $430-439$.

3. Enciso R., Shaw A., Neumann U., Mah J. 3D head anthropometric analysis. Proc. SPIE 5029. Medical Imaging 2003: Visualization, Image-Guided Procedures and Display, 590. doi: 10.1117/12.479752

4. Davis J.P., Valantine T., Davis R.E. Computer assisted photo-anthropometric analyses of full-face and profile facial images. Forensic Sci Int. 2010 Jul 15, vol. 300, no. 1-3, pp. 165-176.

doi: $10.1016 /$ j.forsciint.2010.04.012

5. Smeets D., Claes P., Vandermeulenb D., Clementa J. G. Objective 3D face recognition: Evolution, approaches and challenges. Forensic Sci Int., 2010 Sep 10; vol. 201, no. 1-3, pp. 125-132.

doi: $10.1016 /$ j.forsciint.2010.03.023

6. Fitzgibbon A.W., Zisserman A. Automatic camera recovery for closed or open image sequences. Computer Vision - ECCV'98, vol. 1406 of the series Lecture Notes in Computer Science, pp. 311-326. doi: $10.1007 / \mathrm{BFb} 0055675$

7. Muhamad S., Hebert M. Iterative projective reconstruction from multiple views. Proceedings of the IEEE Conference on Computer Vision and Pattern Recognition (CVPR '00). 2000, june, vol. 2, pp. 430-437.

8. Faugeras O., Luong Q.T., Papadopoulo T. The geometry of multiple images, The MIT Press, 2001.

9. Liu L., Stamos I., Yu G., Wolberg G., Zokai S. Multiview geometry for texture mapping 2D images onto 3D range data. Proc. Computer Vision and Pattern Recognition. 2006, IEEE Computer Society Conference, 2006, vol. 2, pp. 2293-2300. doi: 10.1109/CVPR.2006.204

10. Wu Ch. Towards Linear-time Incremental Structure From Motion. Proceedings of the 2013. International Conference on $3 D$ Vision. IEEE Computer Society Washington, DC, pp. 127-134. doi: $10.1109 / 3$ DV.2013.25

11. Wu Ch. VisualSFM: A Visual Structure from Motion System [Website of Synkera Technologies, Inc.]. Available at: http://ccwu.me/vsfm/ (accessed 31.10.2016).

12. [Website of Synkera Technologies, Inc.]. Available at: https://commons.wikimedia.org/wiki/ File:Sfm1.jpg (accessed 20.02.2016). 